\title{
INFANTICÍDIO, BATISMO, ALMA: TRADUZINDO SENTIDOS
}

Isabel Cristina Hentz*

PROSPERI, Adriano. Dar a alma: história de um infanticídio. São Paulo: Companhia das Letras, 2010.

No dia 5 de dezembro de 1709, em Bolonha, Lucia Cremonini, uma moça jovem, deu à luz a um menino, sozinha, sem a ajuda de ninguém. Tão logo nasceu a criança, a jovem matou-o com uma faca de cozinha. Por este seu ato, foi julgada e condenada à forca. É contando a história de Lucia que Adriano Prosperi inicia seu livro Dar a alma. A partir deste caso específico, não muito especial, segundo o próprio autor, Prosperi constrói um histórico sobre o infanticídio e sobre seus significados em diferentes tempos e espaços, partindo da Antiguidade para chegar ao início da Modernidade, chegando a tocar algumas vezes os dias atuais, percorrendo a Europa e passando, brevemente, pelo Novo Mundo e pelo Oriente.

Para dar conta de explicar os personagens, suas ações e os significados sociais de suas ações ao longo do tempo, o autor divide o livro em três partes: A história; Os atores: pessoas e não pessoas; e A justiça. Na primeira parte do livro, Prosperi utiliza como ponto de partida a história do processo de Lucia para traçar um histórico amplo da "prática social" do infanticídio, mostrando o processo de mudança da percepção - de pecado a crime - desta prática. Segundo o autor, o infanticídio, apesar de ser uma prática comum e constante no mundo da sociabilidade feminina, era uma obsessão e foi utilizado como forma de condenar grupos sociais estigmatizados; é o caso dos hebreus, dos hereges e das bruxas, especialmente na Idade Média e início da Modernidade.

É com base em uma hipótese semelhante que a equipe de pesquisadoras e pesquisador, coordenados por Joana Maria Pedro, aborda as práticas de aborto

* Mestranda do Programa de Pós-Graduação em História da Universidade Federal de Santa Catarina (UFSC) e bolsista CAPES/REUNI. E-mail: ichentz@gmail.com 
e infanticídio em Florianópolis no século XX. Na obra Práticas proibidas ${ }^{1}$, uma coletânea de artigos resultante de uma pesquisa realizada em grupo ao longo de cinco anos, as autoras e o autor apresentam um processo de "estranhamento" ao que chamam de "práticas costumeiras de aborto e infanticídio". Segundo o grupo de pesquisa, o aborto e o infanticídio seriam práticas presentes no mundo das experiências e das sociabilidades femininas ao longo da história; no entanto, em Florianópolis durante o século XX, houve um processo de estranhamento, protagonizado pelas autoridades jurídicas, policiais, médicas e pela imprensa, cujo objetivo era tornar estranhas e condenáveis práticas que eram costumeiras até então, estando este processo inserido no contexto de "civilização" do Brasil. A imprensa teve papel importante neste processo, ao noticiar casos de aborto e de corpos de crianças abandonados em locais públicos com palavras fortes, caracterizando as mulheres que cometiam estes atos como "mães-desnaturadas", "bestas" e "feras". Podem ser percebidos muitos pontos de conexão entre a obra de Prosperi e a coletânea sobre Florianópolis; isso nos faz refletir, em consonância com uma abordagem crescente no campo historiográfico, no aborto e no infanticídio, assim como em sua perseguição como pecado e crime, como fenômenos globais, que se manifestam em diferentes lugares e épocas, com semelhanças e diferenças.

Voltando ao livro de Prosperi, a segunda parte é a maior e mais densa do livro e nela o autor aborda o papel social dos personagens e os significados sociais envolvidos em um infanticídio. Esta segunda parte é, por sua vez, dividida em duas partes: A mãe; e O filho, a semente e a alma. Em $A$ mãe, Prosperi fala sobre o lugar social de Lucia, mostrando que era uma mulher "sozinha", ou seja, sem nenhum homem que pudesse ampará-la e quais eram as possibilidades de uma mulher que engravidava nas condições de Lucia: pobre, solteira, órfã de pai, desonrada. O filho, a semente e a alma talvez seja a parte mais original da obra. Ao longo de seis capítulos, Prosperi se propõe a fazer uma "história do não nascido", sobre o menino que morreu, sobre quais eram as expectativas em relação àquele ser e que acabaram no momento em que a mãe cravou a faca na garganta do filho. O filho, a semente e a alma é uma história sobre vida e morte, alma e batismo; o autor mostra que o problema do infanticídio não era a morte de uma criança em si, mas a morte de um ser não batizado, sem alma e, portanto, condenado à danação eterna. Dessa maneira, o autor traça um histórico de como o infanticídio era visto, sempre articulando seu significado com discussões teológicas e científicas de diversos momentos históricos sobre concepção, sobre batismo e sobre alma. A terceira e última parte do livro fala sobre os últimos momentos da vida de Lucia, antes da execução da sentença, e mostra o funcionamento da justiça em casos de infanticídio.

Uma obra que dialoga de forma interessante com a discussão sobre o papel do batismo elaborada por Prosperi, é o livro A morte menina ${ }^{2}$, resultado da 
tese de doutorado de Luiz Lima Vailati. Quando aborda os rituais de preparação para a morte das crianças, o autor faz considerações sobre os papéis social e religioso do batismo no Brasil do século XIX. É surpreendente a quantidade de coincidências entre o que narram o autor brasileiro e o italiano, a despeito da distância temporal e geográfica, tanto em relação às diretrizes oficiais da Igreja Católica, quanto às práticas e aos significados populares relativos ao batismo. Parece que a "obsessão" pelo batismo chegou, também, ao Novo Mundo.

A história de Lucia Cremonini é o ponto de partida da narrativa de Prosperi; contudo, ela não é a personagem principal desta história. O processo do qual foi protagonista, provavelmente o único documento relacionado a esta jovem que chegou até os dias de hoje, é muito pequeno, muito breve, absolutamente comum e com um desfecho nada surpreendente. Para suprir as lacunas do processo de Lucia, para torná-lo mais compreensível e para mostrar outros desfechos possíveis para mulheres infanticidas, o autor utiliza diversos outros processos de infanticídio de vários locais da Europa, em momentos distintos. Lucia é quase como uma "personagem-pretexto"; é a personagem que aparece para contar sua história, mas que logo desaparece para dar lugar a uma história sobre o infanticídio.

No entanto, o fato de não existirem informações nem documentação suficiente para tornar Lucia uma personagem cuja história possa ser mais explorada não a torna menos importante para a narrativa de Adriano Prosperi; é muito interessante a forma como o historiador se utiliza da história desta personagem. A partir do processo de Lucia, Prosperi identifica palavras e expressões utilizadas pela jovem ou pela justiça - muitas vezes utilizadas como títulos para os capítulos - e as traduz para nossos dias, apresentando toda a carga de significados sociais presentes nelas, em diferentes momentos e lugares. Esta é a operação do autor quando mostra o que significava ser uma mulher "sozinha", qual era o peso da morte de um "menininho", especialmente um "bem formado em todas as suas partes".

Outro papel importante de Lucia na narrativa de Prosperi é que sua história abre uma janela para a imaginação histórica, para imaginar - uma vez que não há fontes para afirmar - sobre a sensibilidade. Em vários momentos o autor se pergunta: como Lucia se sentiu? Não o faz procurando algum traço de arrependimento ou de hesitação, mas em uma tentativa de enxergar quais as possibilidades que estavam postas para Lucia em sua situação e porque ela fez aquela escolha. Ela poderia ter escolhido criar seu filho, mas assumiria o papel de mulher desonrada. Ela poderia ter deixado seu filho em um dos locais que cuidavam de crianças abandonadas, mas, segundo as leis de sua cidade, deveria pagar uma quantia em dinheiro, algo que não possuía, e deveria se identificar, novamente assumindo o papel de mulher desonrada. Ela poderia, ainda, ter pedido proteção a algum homem ou até mesmo ao padre 
de sua localidade, mas era órfã de pai, não possuía relações com homens que pudessem protegê-la e seria irônico recorrer a um homem da Igreja, já que o pai da criança que dera à luz era um padre. Não podemos saber se Lucia calculou todas estas possibilidades no momento em que decidira dar fim à vida de seu recém-nascido, mas o autor nos apresenta qual era a margem de manobra de uma mulher como Lucia na situação em que se encontrava.

Dar a alma, publicado originalmente em $2005^{3}$, é o primeiro livro de Prosperi publicado no Brasil. Professor da Scuola Normale Superiore, em Pisa, este historiador italiano é especializado em temas relacionados à Reforma Protestante e à Contra-Reforma Católica, tendo várias obras publicadas nesta área. Prosperi possui algumas publicações em co-autoria com Carlo Ginzburg, historiador muito conhecido no Brasil. Atualmente, Adriano Prosperi pesquisa sobre história da cultura e da vida religiosa no início da Modernidade. ${ }^{4}$

Não é fácil definir o que é o livro de Prosperi - se é um livro de micro-história, sobre mulheres e relações de gênero, ou de História Moderna européia, dentre muitas outras definições possíveis. Também é difícil definir o tema central desta obra. Em um primeiro momento, o tema que parece mais evidente é o do infanticídio, afinal é o que diz o título do livro e é sobre este tema que a primeira parte do livro discorre. Entretanto, os capítulos mais longos e mais densos são sobre o batismo e a alma, nos quais o autor aborda diferentes sentidos destes dois termos em diferentes tempos, espaços e para diferentes grupos sociais. Podemos dizer, então, que o livro não possui um tema principal, mas uma cadeia de temas principais, uma vez que o grande problema do infanticídio é a morte de uma criança não batizada e a grande questão do batismo diz respeito à alma.

Um dos aspectos interessantes do livro de Adriano Prosperi é que, apesar de tratar de discussões morais, filosóficas e teológicas intermináveis, o autor consegue conectar essas discussões com o cotidiano das pessoas comuns; não é um livro marcado apenas pela história intelectual. A discussão sobre em que momento a alma se insere no ser humano - se é no batismo, ou após 40 dias para os meninos e 80 dias para as meninas, ou ainda se é até três dias após a concepção ou no próprio momento da concepção - poderia correr o risco de se tornar enfadonha. Prosperi mostra, porém, que ter claro o momento em que o corpo recebe a alma era importante não só para os intelectuais, mas para todos - e, principalmente, todas. Afinal de contas, a partir do momento em que se define que a alma está presente desde o momento da concepção, cometer um aborto, em qualquer período da gravidez, se torna o assassinato de um ser com alma, portanto um crime capital, passível de punição capital.

Adriano Prosperi, como já foi citado brevemente acima, é um estudioso da Reforma, da Contra-Reforma e das questões relacionadas a estes temas; não é conhecido como um estudioso das relações de gênero. Dar a alma, apesar 
de ser "história de um infanticídio", tema tradicionalmente analisado pelos estudos de gênero, não se restringe ao tema do título, tendo em seu cerne muito mais questões teológicas e filosóficas sobre a alma do que o infanticídio puro e simples. É notável, porém, a forma como o autor analisa as relações de gênero em vários momentos de sua narrativa: o processo de identificação do crime de infanticídio como um crime eminentemente feminino, a importância dada ao nascimento de um menino em relação ao de uma menina, o peso das relações sexuais fora do casamento para homens e mulheres, a diferença do aborto e do infanticídio cometido por mulheres "sozinhas" ou por aquelas inseridas em redes de solidariedade feminina ou proteção masculina. Isso faz refletir sobre a importância dos estudos de gênero e dessa categoria de análise não se configurarem apenas como um campo de pesquisas autônomo. É evidente que pesquisas históricas de fôlego sobre as relações de gênero têm importância em si mesmas na construção do conhecimento sobre o passado. Todavia, isso não significa que são exclusivas desse campo de conhecimento. É importante que a categoria de análise gênero - assim como raça, etnia, classe, geração, religião, dentre tantas outras - estejam presentes no olhar dos historiadores para que possam enxergar as pessoas de outros tempos pela complexidade pela qual são marcadas. ${ }^{5}$ O livro de Prosperi é exemplar para mostrar como é possível se fazer uma análise complexa e rica das relações de gênero, mesmo sem reivindicar o uso deste termo e sem tornar este tema o centro da discussão.

Todo livro de história que lemos, toda pesquisa histórica realizada tem como ponto de partida questões do presente. Uma pergunta sobre o passado não deixa de ser, também e principalmente, uma questão sobre o presente; isso já é conhecido desde o tempo de Marc Bloch. Nem sempre, porém, essas questões são tão evidentes para o leitor. A princípio, um infanticídio cometido em Bolonha no início do século XVIII parece ser um tema muito distante de nossa realidade. No entanto, as discussões sobre quando o corpo em formação passa a possuir alma, qual a autoridade da religião e da medicina em intervir nos corpos das mulheres grávidas podem ser traduzidas, para os nossos dias, em questões como: quando a vida começa, quem deve decidir sobre os corpos das mulheres grávidas e sobre o fruto que carregam - a moral, a ciência ou as próprias mulheres? Novamente, são questões que não se restringem a discussões intelectuais, mas que têm reflexo direto no cotidiano: o direito das mulheres ao próprio corpo e a descriminalização do aborto, pautas feministas desde os anos 1960 e que ainda não foram plenamente alcançadas, são apenas dois exemplos. Dessa maneira, é importante que as questões atuais que inspiram a realização de uma pesquisa histórica sejam escolhas conscientes dos historiadores. É importante, também, que sejam explicitadas como um ato de honestidade e de humildade perante o leitor, mas principalmente como um ato político. 


\section{NOTAS}

${ }^{1}$ PEDRO, Joana Maria (org.). Práticas proibidas: práticas costumeiras de aborto e infanticídio no século XX. Florianópolis: Cidade Futura, 2003.

2 VAILATI, Luiz Lima. A morte menina: infância e morte infantil no Brasil dos oitocentos (Rio de Janeiro e São Paulo). São Paulo: Alameda, 2010.

${ }^{3}$ PROSPERI, Adriano. Dare l'anima. Storia di un infanticídio. Torino: Einaudi, 2005.

${ }^{4}$ Informações retiradas do perfil acadêmico da instituição em que trabalha. Disponível em: $<$ http://www.sns.it/it/lettere/menunews/docenti/prosperi/>. Acesso em: 29 jun. 2011.

5 Para uma maior discussão sobre o uso da categoria gênero de forma "transversal" na pesquisa histórica, ver: PEDRO, Joana Maria. "Relações de gênero como categoria transversal na historiografia contemporânea." Revista Topoi, Rio de Janeiro, 2011-2. (no prelo).

Resenha recebida em agosto de 2011. Aceita em dezembro de 2011. 